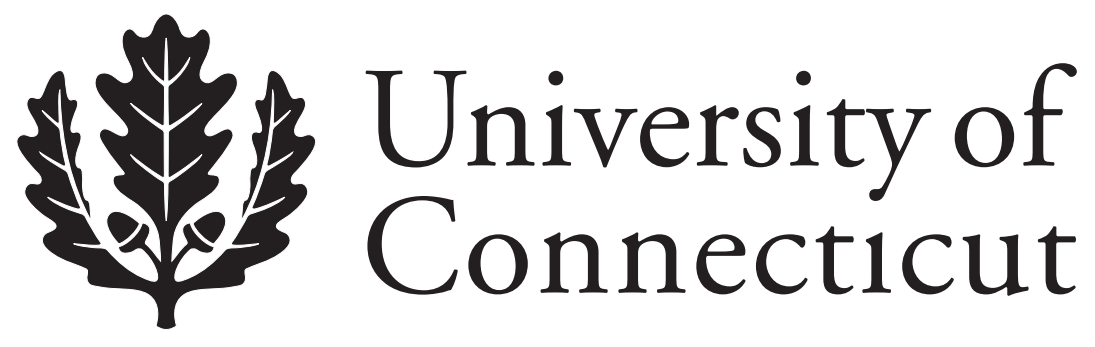

Department of Economics Working Paper Series

\title{
On Negligence Rules and Self-Selection
}

Thomas J. Miceli

University of Connecticut

Working Paper 2006-26

April 2006

341 Mansfield Road, Unit 1063

Storrs, CT 06269-1063

Phone: (860) 486-3022

Fax: (860) 486-4463

http://www.econ.uconn.edu/

This working paper is indexed on RePEc, http://repec.org/ 


\begin{abstract}
Economic models of negligence ordinarily involve a single standard of care that all injurers must meet to avoid liability. When injurers differ in their costs of care, however, this leads to distortions in their care choices. This paper derives the characteristics of a generalized negligence rule that induces injurers to selfselect their optimal care levels. The principal features of the rule are (1) the due standard of care is maximal, and (2) liability increases gradually as injurers depart further from this standard. The results are broadly consistent with the gradation in liability under certain causation rules and under comparative negligence.
\end{abstract}

Journal of Economic Literature Classification: D82, K13

Keywords: Liability, negligence rules, self-selection

I acknowledge the helpful comments of Francesco Parisi, Richard Posner, Steven Shavell, and two referees. 


\section{On Negligence Rules and Self-Selection}

\section{Introduction}

The economic model of negligence beginning with Brown (1973) has generally

focused on the case of a single injurer and a single efficient standard of care. ${ }^{1}$ In reality, of course, injurers have different optimal care levels arising from variation in their costs of care. Actual negligence law nevertheless generally sets a single due care standard (the reasonable person standard) to which all injurers must conform, the argument being that the allocative savings from setting individualized standards would be more than offset by the cost of ascertaining individual costs of care and tailoring standards to those differences (Landes and Posner, 1987, p. 127).

It does not follow from this argument, however, that actual liability rules make no provision for variation in injurer or victim costs of care. For example, Rubinfeld (1987) has argued that when parties to an accident differ in their costs, and these differences are unobservable to the court, it may be possible to structure the liability rule so as to induce the parties to sort themselves out by means of self-selection. Rubinfeld specifically focuses on comparative negligence and shows how the gradual increase in liability as parties depart further from the due standard gives them an incentive to choose their individually optimal care levels rather than clustering (or "pooling") at the due standard, as happens under standard negligence rules.

Recently, Bar-Gill and Ben-Shahar (2003) have suggested that, while Rubinfeld's argument is not wrong, it does not represent a persuasive argument for the superiority of 
comparative negligence because other negligence rules can also induce self-selection. Specifically, if injurers meet the due standard of care under a "simple" negligence rule, then victims bear their own losses and hence choose their individually optimal care levels. Thus, victim self-selection occurs. Similarly, if victims meet the due standard under a rule of strict liability with contributory negligence, then injurers are fully liable and hence self-select their optimal care levels. ${ }^{2}$ The problem with these examples, of course, is that only the party facing liability self-selects, thus bearing out Rubinfeld's original point that negligence rules with a single standard of care cannot induce selfselection by the party to whom the standard applies because of the tendency to cluster at the standard.

This paper re-examines the relationship between negligence rules and selfselection in an effort to clarify the conditions under which various forms of negligence can and cannot achieve efficient sorting. I first show, contrary to the above claim, that negligence rules with a single due standard can induce self-selection by the party to whom the standard applies, but only if two conditions are met. First, the standard must be equal to the optimal care level of the party with the lowest cost of care (i.e., it must be "maximal"), and second, all parties with higher costs must find it optimal to violate the standard. Because there is no way to guarantee that this second condition will be satisfied, however, I go on to derive the characteristics of a generalized negligence rule that always induces self-selection. The key feature of such a rule is that it does not entail

\footnotetext{
${ }^{1}$ For elaborations, see Landes and Posner (1987) and Shavell (1987). The legal counterpart of the economic model of negligence is the Hand test. See U.S. v. Carroll Towing, 159 F.2d 169 (2d Cir. 1947).

${ }^{2}$ The outcome under negligence with a contributory negligence defense would be the same as under simple negligence because, once the injurer meets the due standard, the victim is fully liable, regardless of whether or not she met the contributory negligence standard.
} 
an abrupt jump in liability when the due standard is violated but instead involves a gradual increase as care departs further from the standard.

It will be apparent that a fully efficient sorting rule is not feasible owing to the high informational requirements. Thus, the practical import of the analysis involves identifying features of actual tort law that promote self-selection. In this sense, the results of the model echo Rubinfeld's argument about comparative negligence, and also suggest how certain causality limits in tort law can be interpreted as self-selection devices. ${ }^{3}$

\section{The Model}

To keep the analysis simple, I consider a unilateral care model in which injurers differ in their costs of care. (I suggest below that the results should also extend to the bilateral care case.) In addition I employ a graphical approach to make the results as transparent as possible.

Let the expected accident costs caused by injurer $i$ be

$$
c_{i} x+p(x) D
$$

where $c_{i}$ is his cost of care, $x$ is his level of care, $p(x)$ is the probability of an accident $\left(p^{\prime}<0, p^{\prime \prime}>0\right)$, and $D$ is the victim's damage. Optimal care for injurer $i$, denoted $x_{i} *$, therefore solves the first-order condition

$$
c_{i}+p^{\prime}(x) D=0
$$

from which it follows that injurers with lower costs of care should take more care. ${ }^{4}$

Injurer $i$ 's actual choice of care will depend on his liability in the event of an accident, as dictated by the liability rule, $L_{i}$. That is, injurer $i$ will choose $x_{i}$ to minimize

\footnotetext{
${ }^{3}$ See the discussion in Section 3 below.

${ }^{4}$ Specifically, differentiating (2) yields $\partial x_{i} * / \partial c_{i}=-1 / p^{\prime \prime}<0$.
} 


$$
c_{i} x+p(x) L_{i}
$$

where $L_{i}$ may depend on $x_{i}$, which we assume is observable to the court. It follows from (1) and (3) that a rule of strict liability (i.e., $L_{i}=D$ for all $i$ ) will induce all injurers to selfselect their individually optimal care levels. The question is whether this same result can be achieved under a negligence rule. One way that it can is if the court is able to observe each injurer's cost of care and set individualized standards. In most cases, however, information costs preclude this strategy, forcing the court to set a single standard for all injurers. ${ }^{5}$ If that standard reflects the "average" injurer's costs (as under the reasonable person standard), then two sorts of inefficiencies will result: first, injurers with optimal care levels above the due standard will adjust their care down to the standard, resulting in too little care; and second, injurers with optimal care levels just below the due standard will adjust their care up to the standard, resulting in too much care. Only injurers with optimal care levels well below the due standard will knowingly violate the standard and choose their optimal care levels (Landes and Posner, 1987: Chapter 5). Thus, some selfselection occurs, but the outcome is not first-best because of the pooling of injurers at the due standard.

The preceding seems to imply that when the court cannot observe differences in injurers" costs, a negligence rule with a single standard ("simple negligence") cannot achieve the first-best outcome (perfect separation). This conclusion, however, is not necessarily true. To see why not, consider a negligence rule with a single due standard equal to $\bar{x}$. That is, let 


$$
L_{i}=\begin{array}{ll}
0, & \text { if } x_{i} \geq \bar{x} \\
D, & \text { if } x_{i}<\bar{x},
\end{array}
$$

Also, suppose injurers vary discretely in their costs of care as follows:

$$
c_{1}>c_{2}>\ldots>c_{N}
$$

implying that

$$
x_{1} *<x_{2} *<\ldots<x_{N}^{*}
$$

In this setting, the rule in (4) will result in perfect separation of injurers if two conditions are met: (i) the due standard is set at the optimal care level of the lowest cost injurer (i.e., $\bar{x}=x_{N} *$ ), and (ii) all injurers besides the lowest cost injurer find it optimal to violate the due standard.

We prove this assertion graphically as follows. First, use (3) to derive the slope of the iso-cost curves for a type- $c$ injurer in $(L, x)$ space:

$$
\frac{\partial L}{\partial x}=\frac{c+p^{\prime} L}{-p}
$$

Note that this expression is positive when the injurer's costs are decreasing $\left(c+p^{\prime} L<0\right)$ and negative when his costs are increasing $\left(c+p^{\prime} L>0\right)$. Thus, iso-cost curves are inverted U's with the peak at the point where the injurer's costs are minimized. Further, costs are decreasing as the curves shift down and to the left (i.e., toward lower values of $x$ and $L$ ), and the peaks also shift left, as shown in Figure 1. Thus, the peak occurs at injurer $i$ 's optimal care level when $L_{i}=D$ but at lower care levels for all $L_{i}<D .^{6}$

Finally, note that

\footnotetext{
${ }^{5}$ When an injurer's costs differ from the average person in an obvious (observable) way, as in the case of blind people and certain professionals, the court can and does employ a different standard (Landes and Posner, 1987: p. 127). We therefore focus on cases where the court cannot distinguish among injurers. ${ }^{6}$ We restrict attention to liability rules with $L_{i} \leq D$.
} 


$$
\frac{\partial}{\partial c}\left(\frac{d L}{d x}\right)=\frac{-1}{p}<0,
$$

which implies that the slopes of the iso-cost curves for higher cost injurers are smaller. It follows that the curves for any two types of injurers can intersect only once in $(L, x)$ space. For example, Figure 2 shows the iso-cost curves for two types of injurers, $i$ and $i+1$, where $c_{i}>c_{i+1}$. This "single-crossing property" is a crucial feature of all problems involving self-selection (Cooper, 1984).

Now consider Figure 3, which shows the iso-cost curves for the lowest and nextto-lowest cost injurers ( $N$ and $N-1$, respectively) for the case where the due standard is maximal (i.e., $\bar{x}=x_{N}^{*}$ ). Each of these injurers can either choose to meet the due standard and avoid liability (the point $\left.\left(0, x_{N}^{*}\right)\right)$, or select some lesser level of care and face full damages. Clearly, injurer $N$ minimizes costs by meeting the due standard (given that this is his cost-minimizing level of care anyway), but for the case shown, injurer $N-1$ faces lower costs by violating the due standard and choosing his optimal care level, $x_{N-1}{ }^{*}$. This is true because his iso-cost curve through point $\left(D, x_{N-1} *\right)$, labeled $\mathrm{IC}_{\mathrm{N}-1}$ in Figure 3 , is lower than his curve through $\left(0, x_{N}{ }^{*}\right)$, labeled $\mathrm{IC}_{\mathrm{N}-1}$, , indicating that the former point entails lower costs. It should be clear that, a fortiori, all injurers with higher costs prefer their optimal care levels and full liability to the due standard. As a result, perfect separation occurs.

This conclusion shows that self-selection can be achieved under a simple negligence rule as long as the due standard is set high enough that all but the lowest cost 
injurer chooses to violate it. In equilibrium, therefore, the rule essentially becomes one of strict liability, which we have seen always induces self-selection. ${ }^{7}$

Setting a maximal standard, however, does not guarantee perfect separation (i.e., it is a necessary but not a sufficient condition). To illustrate, consider Figure 4, which shows a case in which injurer $N-1$ prefers to meet the due standard (still set at $x_{N}^{*}$ ) rather than to choose his individually optimal care level. In this case, injurers $N-1$ and $N$ pool at the due standard, and perfect separation does not occur. Algebraically, this outcome arises because for injurer $N-1, c_{N-1} x_{N} *<c_{N-1} x_{N-1} *+p\left(x_{N-1} *\right) D$, or

$$
c_{N-1}\left(x_{N} *-x_{N-1} *\right)<p\left(x_{N-1} *\right) D .
$$

Note that this condition becomes more likely the closer are the optimal care levels of the lowest and next-to-lowest cost injurers, thus making the due standard more attractive. It follows that the separating outcome in Figure 3 requires a sufficient "distance" between $x_{N} *$ and $x_{N-1} *$ so that condition (9) does not hold.

However, when condition (9) does hold, perfect separation can still be achieved by modifying the negligence rule in a particular way. Specifically, starting from the maximal due care standard, liability must increase gradually from zero as injurers choose progressively lower levels of care. This change eliminates the discrete drop in liability at the due standard, thereby reducing the attractiveness to higher cost injurers of adjusting their care levels upward to the standard. To illustrate, return to Figure 4 and note that, in order to avoid pooling at the due standard $\left(x_{N}^{*}\right)$, it is necessary to reduce the cost to injurer $N-1$ of choosing $x_{N-1} *$ rather than $x_{N} *$. This is accomplished by setting an upper bound on the injurer's liability from choosing $x_{N-1} *$ such that he is just indifferent

\footnotetext{
${ }^{7}$ This point is also recognized by Bar-Gill and Ben-Shahar (2003: pp. 458-459).
} 
between choosing $x_{N-1} *$ and $x_{N} *$ The resulting upper bound is shown by $L_{U}^{N-1}$ in Figure 4 and is defined by the equation

$$
c_{N-1} x_{N} *=c_{N-1} x_{N-1} *+p\left(x_{N-1} *\right) L_{U}^{N-1} \text {. }
$$

Thus, for any liability $L_{N-1} \leq L_{U}^{N-1}$, injurer $N-1$ will prefer his optimal care level to the due standard..$^{8}$

At the same time, $L_{N-1}$ cannot be set so low that the lowest cost injurer (injurer $N$ ) finds it cost minimizing to violate the due standard, resulting in a pool at $x_{N-1} *$.

(Obviously this would happen if $L_{N-1}=0$.) To prevent this, there must also be a lower bound on $L_{N-1}$ so that injurer $N$ is just indifferent between $x_{N}{ }^{*}$ and $x_{N-1} *$. This lower bound is shown by $L_{L}^{N-1}$ in Figure 4 and is defined by the equation

$$
c_{N} x_{N}^{*}=c_{N} x_{N-1}^{*}+p\left(x_{N-1}^{*}\right) L_{L}^{N-1}
$$

Together, equations (10) and (11) define the bounds for liability corresponding to $x_{N-1} *$ so as to maintain separation of injurers $N$ and $N-1$.

Next consider injurer $N-2$. The problem now is to maintain separation between injurers $N-1$ and $N-2$; that is, to ensure that injurer $N-2$ chooses $x_{N-2}{ }^{*}$ and injurer $N-1$ chooses $x_{N-1} *{ }^{9}$ To do this, suppose that the actual level of liability associated with $x_{N-1}{ }^{*}$ is $L_{N-1} *$, as shown in Figure 5, where $L_{N-1} *$ is between $L_{L}^{N-1}$ and $L_{U}^{N-1}$ as required above. Figure 5 also shows the iso-cost curves for injurers $N-1$ and $N-2$ through the point $\left(L_{N-1} *, x_{N-1}^{*}\right)$. Based on the above logic, these curves define the range of liability that maintains separation between injurers $N-2$ and $N-1$. Specifically, for any $L_{N-2} \in\left[L_{L}{ }^{N-2}\right.$, $\left.L_{U}^{N-2}\right]$, injurer $N-2$ prefers care of $x_{N-2} *$ to $x_{N-1} *$, and injurer $N-1$ prefers care of $x_{N-1} *$ to

\footnotetext{
${ }^{8}$ This assumes, as is conventional, that when the injurer is indifferent, he chooses the care level intended for him.

${ }^{9}$ It is possible to prove that the conditions guaranteeing self-selection between injurers $N-2$ and $N-1$ are sufficient to maintain separation between $N-2$ and $N$. (This is a consequence of the single-crossing
} 
$x_{N-2} *$ Further, note that the bounds imply that injurer $N-2$ will generally face greater liability than that imposed on injurer $N-1$ at his optimal care level, ${ }^{10}$ but still less than the victim's full damages (given $L_{U}^{N-2}<D$ ).

If we repeat this process for injurers with increasing costs of care, the bounds for liability will continue to shift upward until they eventually encompass the victim's full damages. That is, for some injurer $j<N$, it will be the case that $D \in\left[L_{L}{ }^{j}, L_{U}{ }^{j}\right]$. When that happens, liability for injurer $j$ and all higher cost injurers can be set at $D$, and they will self-select their optimal care levels. The logic is identical to that for the situation in Figure 2 above, where all injurers but the lowest cost injurer found it cost-minimizing to violate the due standard and choose their optimal care levels. That example actually represented a special case of the more general model just described, where the bounds for injurer $N-1$ included $D$ (i.e., $j=N-1$ ), so imposing full liability on all but the lowest cost injurer was consistent with perfect separation. In that case, simple negligence achieved the first-best outcome, but as argued above, that will only be possible if the optimal care levels of the lowest and next-to-lowest cost injurers are sufficiently separated. More generally, a gradual increase in liability will be necessary to prevent pooling at the due standard.

As a final point, it is important to note that the proposed rule, when it involves a gradation in liability, necessarily restricts the combinations of care and liability that an injurer can choose from. Specifically, it limits the available $(x, L)$ pairs to those that (1) satisfy self-selection, and (2) induce efficient care by all injurer types. Consequently, for

property.) More generally, we only need to consider self-selection between "adjacent" injurers. For details, see Cooper (1984) and Bolton and Dewatripont (2005, Chapter 2).

${ }^{10} \mathrm{It}$ is possible, given the non-monotonicity of the iso-cost curves, that the lower bound for $L_{N-2}$ will be less than $L_{N-1}$, but the upper bound will always be above $L_{N-1} *$. 
a given $L$, an injurer is not free to choose any $x$, but must choose the one assigned to it by the liability rule. This "take-it-or-leave-it" feature of the proposed rule is characteristic of all sorting models. In the general case of a continuous variation in injurer types, the proposed rule would take the form of a function, $L(x)$, that assigns a particular level of liability to each care choice, where $L^{\prime}<0 .{ }^{11}$

To be sure, one might object that the cost of designing and implementing such a rule is at least as high as setting individualized standards. Thus, the fully efficient rule does not represent a practical alternative to single-standard negligence rules. The results nevertheless suggest that there are allocative gains to be had from a rule that involves some gradation in liability rather than a discrete jump at the due standard. In the next section, I pursue this insight in the context of actual tort doctrines by asking whether there exist any rules that might promote self-selection in this way, albeit imperfectly.

\section{Discussion of the Results}

The liability rule derived in the previous section departs from the traditional Hand-type rule in two ways. First, the due standard of care (i.e., the standard at which liability drops to zero) must be maximal — that is, it must be based on the characteristics of the lowest cost injurer. In contrast, the bulk of negligence law embodies a due standard that is based on the characteristics of the "average" person (Landes and Posner, 1987, p. 126). Although there are some areas of the law—such as that pertaining to common carriers and certain environmental standards — that hold injurers to "the highest degree of vigilance, care, and precaution," these areas appear to be quite limited (Keeton, et al., 1984, p. 209).

\footnotetext{
${ }^{11}$ In this general case, the injurer chooses $x$ to minimize $c_{j} x+p(x) L(x)$, where $L(x)$ is structured so that the solution to this problem is $x_{j}^{*}$ for all $j$.
} 
The second departure of the proposed rule from the traditional model of negligence is that liability declines gradually rather than abruptly away from the due standard. In contrast to the maximal standard, it turns out that this feature of liability is actually quite descriptive of certain causal limitations in the law of torts. In particular, Grady (1983) and Kahan (1989) have argued that the definition of negligence in (4) is not reflective of actual tort law because it ignores the role of causation in determining liability. That is, injurers who violate the due standard of care are not held liable for all of the victim's losses, but only that portion of the losses that are caused by the injurer's negligence (the cause-in-fact limitation). To illustrate, suppose that a train traveling above the speed limit collides with a car stalled at a crossing, killing the driver. Despite the train's negligence, a proper analysis of the case would not hold the railroad liable for those damages that would have occurred if the train had been traveling at the speed limit. The logic is that the train's negligence (exceeding the speed limit) was not the "cause-infact" of those damages. ${ }^{12}$

In terms of the economic model of negligence, the effect of this limitation on liability is to eliminate the discontinuity in damages at the due care standard. Thus, the injurer's liability increases gradually rather than abruptly as his care level falls below the due standard, a result that is consistent with the generalized negligence rule described in Section 2. Consequently, one interpretation of the cause-in-fact requirement is that it allows injurers with differing costs of care to sort themselves out according to their individually-optimal care levels, rather than forcing them to cluster at the single due care

\footnotetext{
${ }^{12}$ See Perkins v. Texas and New Orleans Ry. Co., 243 La. 829, 147 So.2d 646 (1962).
} 
standard. ${ }^{13}$ In short, it transforms the standard negligence rule into a self-selection device exactly along the lines of the analysis in Section 2.

Finally, although the analysis to this point has been conducted in the context of a unilateral care model, the general conclusions should also extend to the bilateral care case. In particular, under comparative negligence both injurers and victims will perceive that their liability increases gradually (rather than abruptly) as they deviate further from the due standard (taking as given the behavior of the other party). As a result, both will find it desirable to tailor their care choices to their individual costs of care rather than clustering at the due standard (the Rubinfeld position). It is likely, however, that the sorting will be imperfect on both sides. (It will depend on the distribution of injurer and victim costs and the compatibility of the self-selection constraints, given the requirement that the injurer's and victim's shares of liability must sum to one). In contrast, single standard rules induce perfect sorting on one side and pooling on the other (the Bar-Gill and Ben-Shahar position). ${ }^{14}$ Thus, the relative desirability of comparative negligence compared to single standard rules in this regard will depend on whether imperfect sorting on both sides results in lower overall costs than perfect sorting on only one.

\section{Conclusion}

It is often argued that negligence rules are costlier to implement than strict liability because negligence requires the court to establish a due standard of care, and then to compare the injurer's actual care to it. Administrative costs would be even higher if courts sought to individualize standards based on differences in injurer costs of care.

\footnotetext{
${ }^{13}$ Along these same line, Schwartz (1998, p. 560) notes that "if an injurer who fails to take the required level of care is liable only for the harm which would have been prevented by taking the required level of care, the injurer will take optimal care rather than the greater level of care required under the legal standard."
} 
By setting a single standard for all injurers (the reasonable person standard), courts therefore save on administrative costs, but in so doing, they potentially create distortions in the care choices of injurers around the due standard.

The purpose of this paper was to show that there exists a class of negligence rules that can eliminate these distortions without the need for the court to observe individual injurers' (and victims') costs of care. The key features of such a rule are: (1) the due standard is set at the optimal care level of the lowest cost injurer, and (2) liability is positive and increasing as injurers depart further from the due standard. Although this rule is broadly consistent with limitations in liability implied by the cause-in-fact rule, and also with the gradation of liability under comparative negligence, it does entail a greater administrative burden on courts compared to simple negligence. Thus, the allocative benefits of the proposed changes must be weighed against these higher costs.

\footnotetext{
${ }^{14}$ Strict and no liability also induce perfect sorting on one side but no care on the other, a situation that is presumably inferior to pooling at the due standard.
} 


\section{References}

Bar-Gill, Oren, and Omri Ben-Shahar. 2003. "The Uneasy Case for Comparative Negligence," 5 American Law and Economics Review 433-469.

Bolton, Patrick, and Mathias Dewatripont. 2005. Contract Theory. Cambridge, MA: MIT Press.

Brown, John. 1973. "Towards and Economic Theory of Liability," 2 Journal of Legal Studies 323-349.

Cooper, Russell. 1984. "On Allocative Distortions in Problems of Self-Selection,” 15 Rand Journal of Economics 568-577.

Grady, Mark. 1983. “A New Positive Economic Theory of Negligence," 92 Yale Law Journal 799-829.

Kahan, Marcel. 1989. "Causation and Incentives to Take Care under the Negligence Rule," 18 Journal of Legal Studies 427-447.

Keeton, W. Page, Dan Dobbs, Robert Keeton, and David Owen. 1984. Prosser and Keeton on Torts, $5^{\text {th }}$ Ed., St. Paul, Minn.: West Publishing Co.

Landes, William, and Richard Posner. 1987. The Economics Structure of Tort Law. Cambridge: Harvard Univ. Press.

Rubinfeld, Daniel. 1987. "The Efficiency of Comparative Negligence," 16 Journal of Legal Studies 375-394.

Schwartz, Warren. 1998. "Legal Standards of Care," in Peter Newman, ed., The New Palgrave Dictionary of Economics of the Law. New York: Stockton Press.

Shavell, Steven. 1987. Economic Analysis of Accident Law. Cambridge: Harvard Univ. Press. 


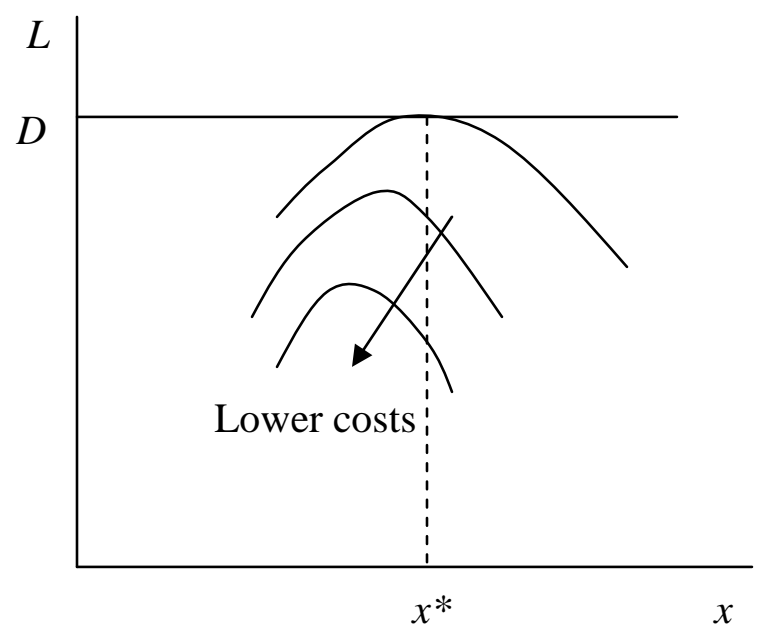

Figure 1. Iso-cost curves in $(L, x)$ space.

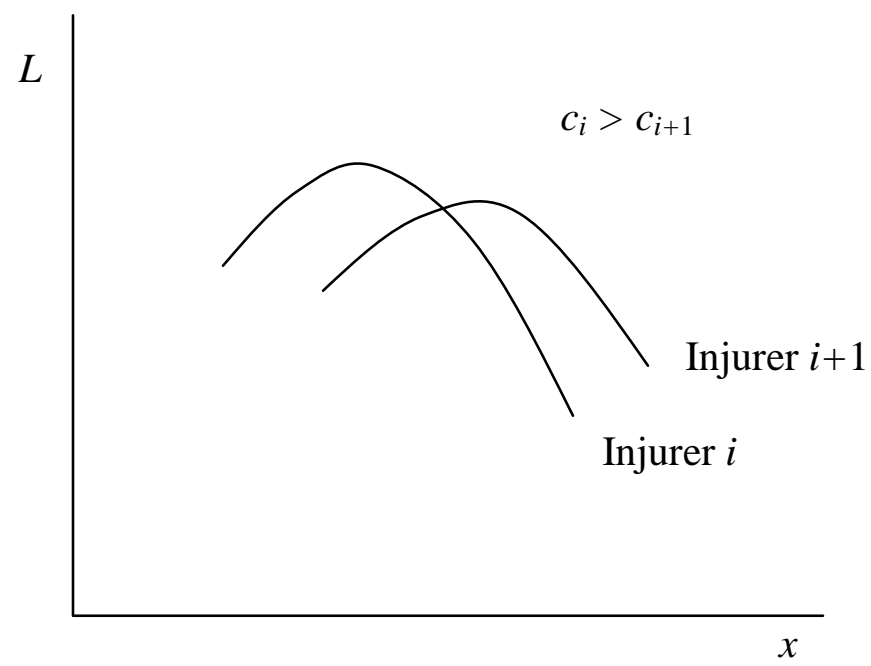

Figure 2. The single-crossing property. 


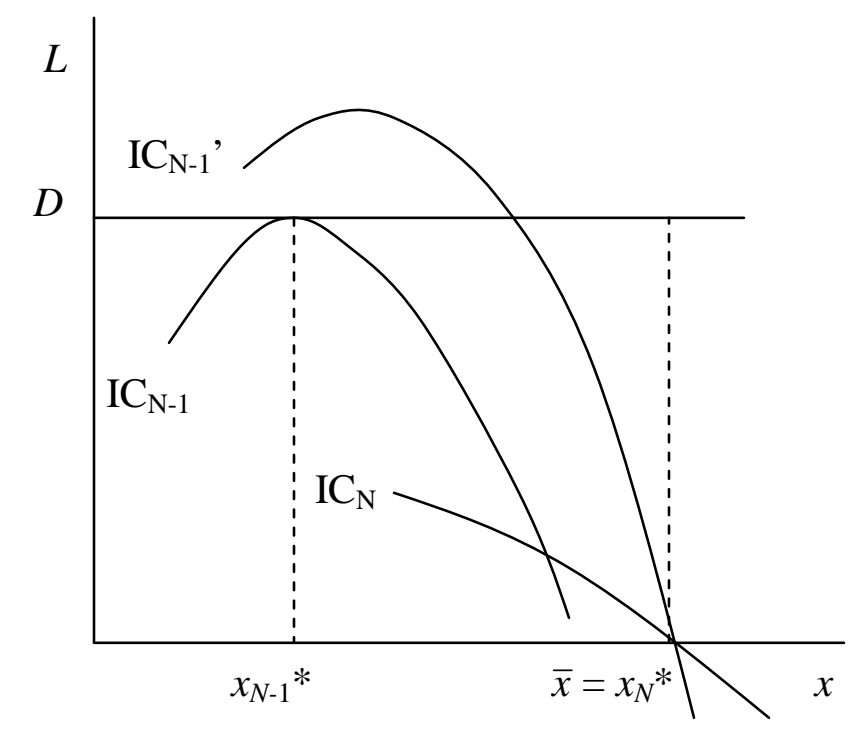

Figure 3. The case where simple negligence achieves perfect separation.

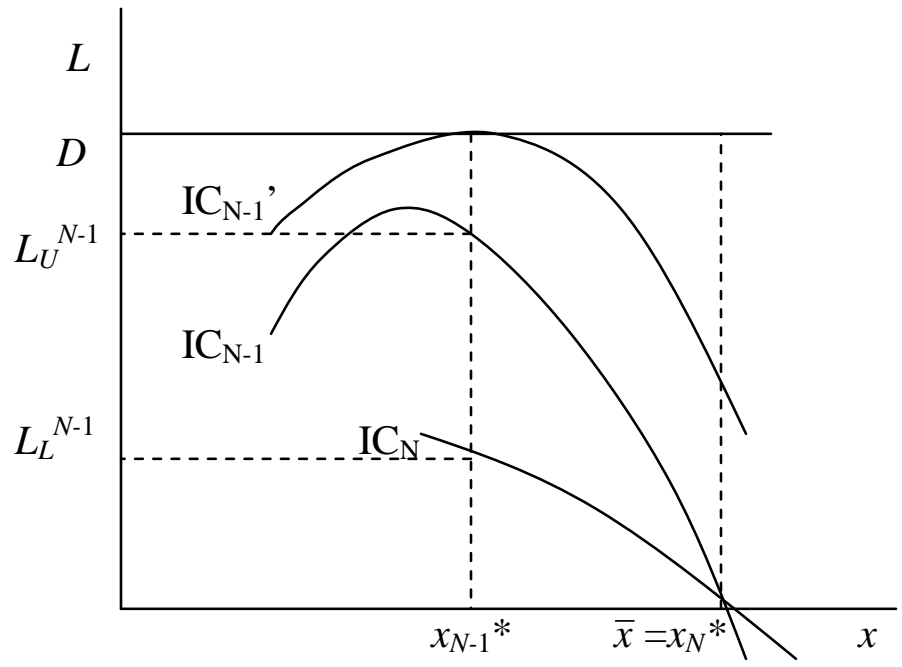

Figure 4. The case where injurers $N$ and $N-1$ pool at the due standard under simple negligence. 


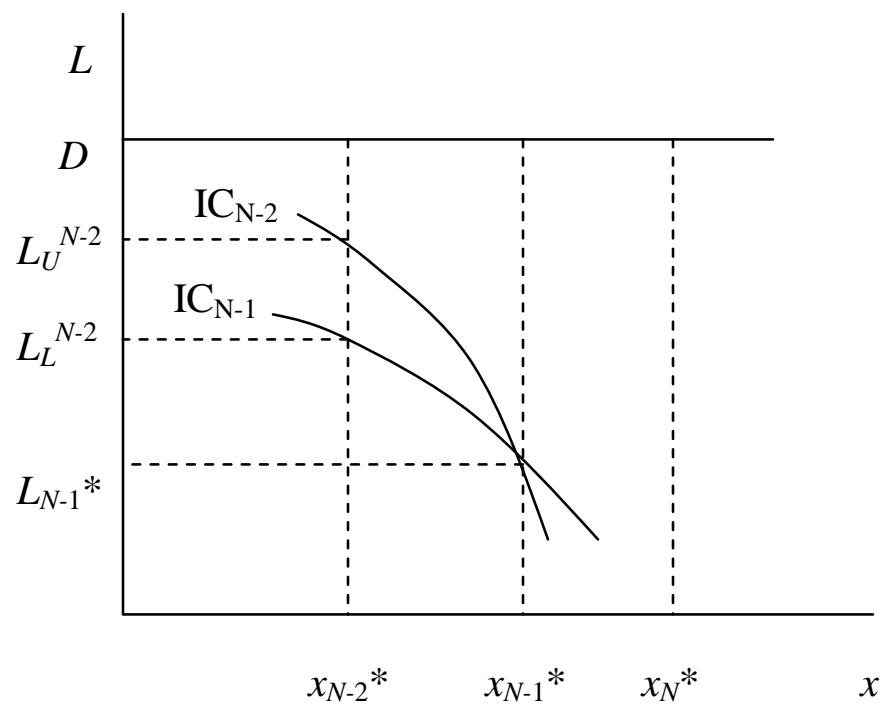

Figure 5. Range of liability that maintains separation between injurers $N-2$ and $N-1$, given $L_{N-1}$ * 